\title{
Miscarriage and Associated Factors: a Hospital Based Cross- Sectional Study in Bangladesh
}

\section{Rashed A* and Sumaiya A}

Department of Population Science and Human Resource Development, University of Rajshahi, Bangladesh

*Corresponding author: Dr. Md. Rashed Alam, Associate Professor, Department of Population Science and Human Resource Development, University of Rajshahi, Bangladesh, Email: mrasps29@gmail.com

\section{Research Article \\ Volume 5 Issue 2}

Received Date: October 20, 2021

Published Date: December 28, 2021

DOI: $10.23880 /$ phoa-16000193

\section{Abstract}

Miscarriage is one of the common, however devastating pregnancy outcomes. In this study experience of miscarriage is investigated from a socio-demographic view point in Bangladesh context. The principal aim is to identify the determinants of miscarriage experienced by currently pregnant women. Primary data used for the analysis and it's extracted from one public and another three private hospitals and clinic at Rajshahi City in Bangladesh to a purposive sample of 418 ever married women aged 15-49 years. A contingency analysis was first constructed to identify the important relations based on experience of miscarriage by various selected socio-demographic characteristics. Then binary logistic regression analyses were integral to evaluate the significance of these interactions along with the individuals risks factors. The study results showed that $11.2 \%$ ever married currently pregnant women were having of experience of miscarriage. Duration of pregnancy period mean score is 9.34 weeks and the number of child score is 0.66 , and most of important thing around $44 \%$ women have no child but they are currently pregnant and among them 45 women experience of miscarriage. The study shows that the women who are in the age group 30 years and above they are higher risk of miscarriage compare in the women of age 15-19 years (OR 63.04 with $95 \% \mathrm{CI}, 3.35$ - 1.37E3). Similarly higher educated women are higher risk of miscarriage compare to illiterate women (OR 18.01 with 95\% CI, 2.19-1.169E3). Controversial result shows well-balance diet during pregnancy period and its reveal that the women get well-balance diet during pregnancy has higher risk of miscarriage compare to the women who get regular foods (OR 2.06 with 95\% CI, 1.21-14.23). Besides knowledge and skills, education might also increase awareness about miscarriage. Finally, it can be concluded that an opportunity to improve a reproductive health education for public health intervention. Marriage would be done in appropriate time and get babies within couple of days after marriage. Global pre-conception healthcare programs successfully provide health promotion strategies to increase knowledge and awareness about miscarriage. In Bangladesh, it would also be relevant to implement global programs and strategies on pregnancy care as well as on the prevention of miscarriage.

Keywords: Knowledge; Awareness; Experience; Miscarriage; Binary Logistic Regression Analysis and Bangladesh

\section{Introduction}

Miscarriage is a common, however, devastating pregnancy outcome which has been gaining some public health concerns. The occurrence of miscarriage varying from about $10 \%$ to $25 \%$ of all pregnancies with a variety of medical reasons, many of which aren't within a person's control [1-4]. Nevertheless, knowing the risk factors, signs, 
and causes of miscarriage can help to better understand the event and get any support or treatment may need, while most of the women, particularly in developing countries including Bangladesh do not have sufficient knowledge about the danger signs or adverse effects of miscarriage.

About 1 in 10 women will have a miscarriage over a lifetime. Globally, an estimated 23 million miscarriages occur every year (NBK 2020). In Bangladesh, it is estimated that one out of four clinically recognized pregnancies will end in miscarriage during the first-trimester, and about $1 \%$ of pregnant women will experience a second-trimester miscarriage [5]. Early marriage is customary, childbearing starts early and progresses fast and also chronic malnutrition is common in Bangladesh. More than two-thirds of rural females are married by the age of 20 [6]. Early childbearing, is considered a successful outcome in rural Bangladesh, however, the risk of miscarriage remained higher among adolescent pregnancies [7]. This risk also begins to increase over the age of 45 , and in some cases about $25 \%$ of women have two or more times miscarriages. Also, a shorter inter pregnancy interval after miscarriage contributes the greater the chance of a miscarriages Women with inter pregnancy intervals less than 18 months after miscarriage, as well as especially more than 48 months, both who are more likely to experience another miscarriage [8-12]. However, the relative risk of a miscarriage was found to be higher for the longest inter pregnancy intervals. A very short interval after a miscarriage (less than 3 months) following another miscarriage was found to be associated with higher mortality risks for infants in Bangladesh [9,12-15]. Most of the available literature has focused on the recommendations for waiting time to conceive again after a miscarriage.

Though miscarriage occurs unexpectedly and can occur in both healthy and complicated pregnancies, some sociodemographic and health factors can also be considered as source of miscarriage risk. However, there is still a lack of understanding about the prevalence and risk factors of miscarriage among the women in Bangladesh [16]. The present analysis aims to make important systematic contributions to identify the groups of multiple sociodemographic characteristics those contributed to significant effects on miscarriage. Prominently, in this study the risk profile is characterized by the interaction of different socio-demographic traits of married pregnant women to allow the possibility of experiencing targeted miscarriage women. The aim of the present study thus requires deep analysis to explore the natural peculiarities of the married pregnant women and their present situation awareness and experience of miscarriage. Therefore, this study investigates the knowledge and concern of married pregnant women about miscarriage, and examines the socio-demographic determinants of miscarriage

\section{Data and Methodology}

The present study is based on a health-facilitybased cross-sectional survey conducted among currently pregnant women from three private hospitals (Islamic Bank hospital, Popular Diagnostic Centre and Royal Hospital) in Rajshahi City, Bangladesh. A number of 415 currently pregnant women who were seeking antenatal care in those health facilities were selected using purposive sampling method. After obtaining permission from the appropriate hospital authority, a direct interview was conducted from 01 July to 30 July 2020. After providing written informed consent, women were requested to complete a pre-tested structured questionnaire administered by a trained female interviewer. Before the interview, women were learned that their participation was completely voluntary, there were no personal identification in the questionnaire, and that they could leave the interview at any time if they were not comfortable answering the questions. Details on data collection procedure are available elsewhere $[17,18]$.

\section{Outcome Variable}

Experience of miscarriage remained the primary outcome in this study. Miscarriage is defined as a "nonviable, intrauterine pregnancy with either an empty of gestational sac or a gestational sac containing an embryo or fetus without fetal heart activity within the first 12 weeks and six days of gestation" [5]. This occurrence refers to spontaneous loss of a provable pregnancy. Provability refers to a fetus weighing $<500$ gram or at gestational age $(\mathrm{GA})<20$ weeks [19]. The most common symptom of a miscarriage is vaginal bleeding with or without pain [20]. Simple Miscarriage or spontaneous abortion is generally defined as the spontaneous lost of a provable pregnancy. Provability refers to a fetus weighing $<500$ gram or at gestational age (GA) $<20$ weeks [19]. Among the women who know they are pregnant, the miscarriage rate is roughly about $10 \%$ to $20 \%$, while the rate among all fertilization is around $30 \%$ to $50 \%$ [21-24]. In this study, a number of 415 pregnant women were assessed for ever experience of miscarriage.

\section{Predictor Variables}

Several theoretical relevant demographic and socioeconomic attributes of currently pregnant women were included as the predictor variables in this study: respondent's current age (15-19, 20-24, 25-29 and 30+); age at marriage (less than 18 years, and 18 years and above); number of children $(0,1$, and $1+$ ), intra pregnancy interval (less than 24 months, and 24 months and above); level of education (no education, primary, and secondary or higher); working status (no, and yes); religion (non-Muslim, and Muslim); place of residence (urban and rural); husband's level of 
education (no education, primary, and secondary or higher); and spousal age difference (less than 3 years, 3-5 years, and more than 5 years).

\section{Statistical Analysis}

The responses obtained from the study population were analyzed using both descriptive statistics (frequency distribution and chi-square association), and bivariate analysis. To measure the influence of selected sociodemographic attributes on experience of miscarriage by women were identified by binary logistic regression analysis [25-27]. The results of the analyses are presented in Table 1.

\begin{tabular}{|c|c|c|c|c|}
\hline $\begin{array}{l}\text { Socio-demographic } \\
\text { variables }\end{array}$ & Group & $\begin{array}{l}\text { N\% of the study } \\
\text { participants }\end{array}$ & $\begin{array}{c}\text { N\% of experience about } \\
\text { miscarriage }\end{array}$ & $P$ values \\
\hline \multirow{4}{*}{ Age of Women } & $15-19$ years $s$ & $110(29.6)$ & $6(12.8)$ & \multirow{4}{*}{0.000} \\
\hline & 20-24 years & $132(35.6)$ & $5(10.6)$ & \\
\hline & $25-29$ years & $103(27.8)$ & $6(12.8)$ & \\
\hline & 30 years and above & $26(7.0)$ & $30(63.8)$ & \\
\hline \multirow{2}{*}{ Religion } & Muslims & $294(79.2)$ & $34(72.3)$ & \multirow{2}{*}{0.183} \\
\hline & Non-Muslims & 77 (19.8) & $13(27.7)$ & \\
\hline \multirow{2}{*}{ Contraceptive use } & No & $93(25.1)$ & $6(12.8)$ & \multirow{2}{*}{0.040} \\
\hline & Yes & $278(74.9)$ & $41(87.2)$ & \\
\hline \multirow{3}{*}{ Women education } & Illiterate & $128(34.5)$ & $6(12.8)$ & \multirow{3}{*}{0.000} \\
\hline & Secondary & $147(39.6)$ & $7(14.9)$ & \\
\hline & Higher & $96(25.9)$ & $34(72.3)$ & \\
\hline \multirow{3}{*}{ Husband education } & Illiterate & $39(10.5)$ & $6(12.8)$ & \multirow{3}{*}{0.005} \\
\hline & Secondary & $145(39.1)$ & $7(14.9)$ & \\
\hline & Higher & $187(50.4)$ & $34(72.3)$ & \\
\hline \multirow{2}{*}{ Place of residence } & Rural & $109(29.4)$ & 7 (14.9) & \multirow{2}{*}{0.023} \\
\hline & Urban & $262(70.6)$ & $40(85.1)$ & \\
\hline \multirow{2}{*}{ Age at marriage } & 17 years and less & $180(48.5)$ & $8(17.0)$ & \multirow{2}{*}{0.000} \\
\hline & 18 years and above & $191(51.5)$ & $39(83.0)$ & \\
\hline \multirow[t]{2}{*}{ Working status } & No & $164(44.2)$ & $6(12.8)$ & 0.000 \\
\hline & Yes & $207(55.8)$ & $41(87.2)$ & \\
\hline \multirow{2}{*}{ Duration of pregnancy } & Lowest through 25 weeks & $193(52.0)$ & $31(66.0)$ & \multirow{2}{*}{0.049} \\
\hline & 26 weeks and above & $178(48.0)$ & $16(34.0)$ & \\
\hline \multirow{4}{*}{ Place of treatment } & RMC & $122(32.9)$ & $5(8.5)$ & \multirow{4}{*}{0.001} \\
\hline & Islamic Bank & $80(21.6)$ & $17(36.2)$ & \\
\hline & Popular diagnostic & $109(29.4)$ & $22(46.8)$ & \\
\hline & Royal & $60(16.2)$ & $4(8.5)$ & \\
\hline \multirow{2}{*}{ Family types } & Single & $248(66.8)$ & $29(61.7)$ & \multirow{2}{*}{0.292} \\
\hline & Joint & $113(33.2)$ & $18(38.3)$ & \\
\hline \multirow{3}{*}{ Family income } & Lowest through 15000 & $134(36.1)$ & $8(17.0)$ & \multirow{3}{*}{0.000} \\
\hline & Between 15001-30000 & $52(14.0)$ & 0 & \\
\hline & 30001 and above & $185(49.9)$ & $39(83.0)$ & \\
\hline
\end{tabular}




\begin{tabular}{|c|c|c|c|c|}
\hline \multirow{3}{*}{ BMI } & Underweight & $41(11.0)$ & $5(10.5)$ & 0.038 \\
\cline { 2 - 4 } & Healthy weight & $273(73.6)$ & $6(12.8)$ & \\
\cline { 2 - 4 } & Overweight & $57(15.4)$ & $36(76.7)$ & 0.000 \\
\hline $\begin{array}{c}\text { Well-balance diet during } \\
\text { pregnancy }\end{array}$ & Yes & $136(36.7)$ & $11(23.4)$ & \multirow{2}{*}{0.394} \\
\cline { 2 - 4 } Knowledge of miscarriage & No & $235(63.3)$ & $2(4.3)$ & \multirow{2}{*}{0.000} \\
\cline { 2 - 4 } & No & $246(93.3)$ & $45(95.7)$ & \\
\cline { 2 - 5 } No. of Child & Yes & $139(37.5)$ & $2(4.3)$ & 0 \\
\cline { 2 - 5 } & No Child & $30(8.1)$ & & \\
\hline
\end{tabular}

Table 1: Distribution of the experience of miscarriage by socio-demographic variables (categorical and continuous) among the women aged 15-49 years

\section{Findings of the Study}

Characteristics of Study Population and Pattern of Miscarriage: The overall experience of miscarriage among the study population was about $21.2 \%$. The mean age of the women was about 23.1 years, and the mean age at marriage was 18.4 years. More than $50 \%$ of pregnant women already had a child. About 58.4\% women had more than 24 months' intra-pregnancy interval whereas about $51.4 \%$ had less than 24 months interval between a miscarriages to their current pregnancy. Furthermore, about $39.6 \%$ were primary completed having secondary completed husbands (more than 50\%). Additionally, most of the respondents were Muslim (79.2\%), not working (65.8\%), and were living in urban areas (70.6\%) (Table 1). The results of analyses reveal that about $53.8 \%$ of women aged 30 years and above had miscarriage before their current pregnancy. About 62.2\% women who married 18 years and above had experienced of miscarriage, whereas about $37.8 \%$ women had miscarriage who married 17 years and under. The mean of educational status of the women and their partners were 9.5 years and 10.0 years and their standard deviation were 5.2 and 5.0 respectively. The experience of miscarriage was lowest among those women who had higher education $(22.3 \%)$ whereas it was higher for those who do not have any education (52.8\%). The experience of miscarriage was little higher in rural area $(51.1 \%)$ than in urban area $(48.9 \%)$. About $48.7 \%$ women who had a paid job had experienced a miscarriage; on the other hand, about $51.3 \%$ women experienced a miscarriage who was not working (Table 1 ).

\section{Determinants of Miscarriage}

Results from the logistic regressions analysis (Table 2) shows multiple socio-demographic variables in the study exhibits experience of miscarriage. The results of analyses show that the age of women, particularly more than 30 years of age significantly affects the experience of miscarriage (OR 1.23) and their younger counterparts. Incidence of miscarriage is found to be higher in firth pregnancy, thus had about 0.89 and 0.78 times low risks after one and more than one pregnancies respectively. The experience of miscarriage significantly lower among women with higher levels of education -0.88 times and 0.85 times lower for those women who had completed primary and high levels of education respectively. Those women who live in urban areas had 0.36 times less risk of miscarriage compared to those women live in rural areas. However, women's work and religious status were not found to have any significant effects on the experience of miscarriage. Although husband's level of education identified as insignificant, spousal age different was found as significantly associated with the occurrence of miscarriage (Table 2).

\begin{tabular}{|c|c|c|c|}
\hline Socio-Demographic Factors & Group & OR (95\% CI) & P Values \\
\hline \multirow{3}{*}{ Age of Women } & $15-19$ years & 1 & \\
\cline { 2 - 4 } & $20-24$ years & $2.94(1.05-9.56)$ & 0.03 \\
\cline { 2 - 4 } & $25-29$ years & $4.50(0.29-14.56)$ & 0.089 \\
\cline { 2 - 4 } & 30 and above & $63.04(3.35-1.37 \mathrm{E} 3)$ & 0.001 \\
\hline
\end{tabular}


Public Health Open Access

\begin{tabular}{|c|c|c|c|}
\hline \multirow{3}{*}{ Educational Status of the Women } & Illiterate & 1 & \\
\hline & Intermediate & $4.03(1.37-15.141)$ & 0.03 \\
\hline & Higher education & $18.01(2.19-1.169 \mathrm{E} 3)$ & 0.041 \\
\hline \multirow{2}{*}{ Working Status of Women } & Yes & 1 & \\
\hline & No & $0.619(0.14-0.79)$ & 0.007 \\
\hline \multirow{2}{*}{ Age at Marriage } & Lowest through 17 Years & 1 & \\
\hline & 18 Years and above & $3.56(0.52-24.38)$ & 0.196 \\
\hline \multirow{2}{*}{ Place of Residence } & Urban & 1 & \\
\hline & Rural & $0.355(0.140-0.92)$ & 0.032 \\
\hline \multirow{2}{*}{ Well-balance diet During Pregnancy } & NO & 1 & \\
\hline & Yes & $2.06(1.21-14.23)$ & 0.023 \\
\hline \multirow{3}{*}{ BMI of the respondents } & Under weight & 1 & \\
\hline & Healthy weight & $0.69(0.22-0.92)$ & 0.022 \\
\hline & Over weight & $1.76(1.18-10.37)$ & 0.039 \\
\hline \multirow{2}{*}{ Place of Treatment } & Private & 1 & \\
\hline & Government & $0.860(0.28-0.92)$ & 0.041 \\
\hline \multicolumn{4}{|c|}{ Experience of miscarriage before this pregnancy } \\
\hline No (Control population) & \multicolumn{3}{|c|}{78.8} \\
\hline Yes (Target population) & \multicolumn{3}{|c|}{21.2} \\
\hline \multicolumn{4}{|c|}{ Model summary } \\
\hline Model $\chi 2(\rho$-value $)$ & $389.314(<0.0001)$ & \multirow{4}{*}{\multicolumn{2}{|c|}{ Overall percentage $=91.6$}} \\
\hline-2 log likelihood & 190.157 & & \\
\hline Cox \& Snell R-square & 0.606 & & \\
\hline Nagelkarke R-square & 0.808 & & \\
\hline
\end{tabular}

Table 2: Experience of miscarriage and associated inference factors results from Binary Logistic Regression Analysis.

\section{Discussion}

The present study assesses the role of different socioeconomic and demographic attributes in explaining the experience of miscarriage by a number of currently pregnant women who were receiving antenatal care from three reputed clinics in Rajshahi city of Bangladesh. In this study, about $21.2 \%$ of women were found to experience miscarriage before their current pregnancy. The findings from the twostep analysis provided several interesting perspectives. In the exploratory part of the analysis, the contingency analysis identified the relationship between various sociodemographic variables and miscarriage, and the second part was binary logistic regression analysis which shows the risk of several selected socio-demographic variables on the experience of miscarriage. Age is an important factor that play vital role of miscarriage, in the present contingency analysis results revealed that age was significantly associated with miscarriage and the same result observed in logistic regression analysis. In this study showed that the women who were in the age group 20-25 years and 30 years and above were 4.5 times and 63 times higher risk of miscarriage comparatively to the age of 15-19 years of women. The same results observed an increasing risk of miscarriage, with increasing maternal age [28-32].

Education is often a local problem, which requires work to determine the best use of resources within the local education system and within the community. If we can well educate of women, they can make our country more beautiful. Women educational attainment was significantly associated with miscarriage and the same result show in logistic regression analysis. The same result show the increased of education status and the higher risk of miscarriage [33-37].

Age at marriage and place of residence is closely related in Bangladesh and around $62.9 \%$ people lived in rural or village areas [38]. The minimum legal age for marriage in Bangladesh is 18 years for girls and 21 for boys. However, the Child Marriage Restraint Act 2017 includes a loophole where a court can allow child marriage in "special cases" for both girls and boys [39]. However, the study found that about $48 \%$ of women married before the age of 17 years. 
But interesting mater is that the women who get married early they are less complicated to miscarriage, the similar results showed $[40,41]$, but in these study. Whereas The women who lived village areas they were at higher risk of miscarriage compared to town areas, and the same results shown in several previous studies [42-44].

\section{Conclusion and Practical Implications}

This study shows that the investigation of the underlying causes of miscarriage and the continuity of care in subsequent pregnancies are a priority for those who experience miscarriage. The provision of appropriate clinical information as well as helpful information is important when advising miscarriage victims. According to the results, only $11.2 \%$ ever married currently pregnant women were having experience of miscarriage. The present study reveals rather a low level of knowledge and awareness on specific aspects of miscarriage, including risk factors, treatment, and content of the law in particular. The provision of adequate care is, however, hampered by a number of obstacles, including a lack of knowledge and awareness, feelings of disability, and fear of self-awareness. To reduce these barriers, it is advisable to include the issue of miscarriage knowledge and awareness in educational level. The educational level, which provides adequate knowledge and (technical, communication) skills, is the key to helping married women gain confidence and take on the role of miscarriage. Moreover, having adequate knowledge and skills helps married women to manage pregnancy loss in a constructive way, and to promote effective care. Besides knowledge and skills, education might also increase awareness about miscarriage. Finally, it can be concluded that an opportunity to improve a reproductive health education for public health intervention. Marriage would be done in appropriate time and get babies within couple of days after marriage. Global pre-conception healthcare programs successfully provide health promotion strategies to increase knowledge and awareness about miscarriage.

\section{Limitations}

The nature of the study design implies that the data were collected at three-month duration. Previous studies have found an association between ethnicity and the perception of risk factors for miscarriage [45], however we did not include this information in our survey and no comparison can be made. One of the main limitations of these study all of the respondent were currently pregnant. Although this study used a semi-structured self-administered questionnaire, various measures were taken to ensure the validity of the questionnaires. The question form was based in part on Knowledge, awareness and experience study questions similar to Capone's [46]. An extensive literary study was conducted to confirm the validity of the content of each item in the knowledge section. A multidisciplinary team specialized in pregnancy loss developed and reviewed all questions. In addition, a patient advocate for women who experience pregnancy loss also reviewed the questionnaire to ensure clarity. Bangladesh does not have any country wise database on miscarriage. The studies on miscarriages mainly determined by survey analyses and to our knowledge, this is one of the largest studies exploring the risk factors for miscarriage among ever married pregnant women in Rajshahi City in one public and another three private hospitals, representing the main strength of this study [47].

\section{Informed Consent}

Consent was obtained from all participants and data collectors included in the study.

\section{Acknowledgements}

I would like to thank all participants who contributed to this study and Dean Faculty of Science.

\section{Disclosure Statement}

The authors declared no conflicts of interest with respect to the research, authorship, and publication of this article.

\section{Ethics Approval}

This study was approved by the Directors of the Institutional Review Board of three selected private hospitals.

\section{References}

1. Buysse A, Enzlin P, Lievens J, TSjoen G, Van Houtte M, et al. (2013) Sexpert Basisgegevens van de survey naar seksuele gezondheid in Vlaanderen. Academia Press, pp: 458.

2. Carnarneiro A, Maciel J, da Silveira R (2015) Experiences of spontaneous abortion in primigravidae during the first trimester of pregnancy: a phenomenological study. Revista de Enfermagem Referencia 5: 109-118.

3. Pflueger SMV (2013) The Cytogenetics of Spontaneous Abortion. The Principles of Clinical Cytogenetics. Springer, pp: 275-292.

4. Tulandi T, Al-Fozan HM (2015) Spontaneous abortion: Risk factors, etiology, clinical manifestations, and diagnostic evaluation.

5. (2015) American College of Obstetricians and Gynecologists practice bulletin no 150. Early pregnancy 


\section{Public Health Open Access}

loss. Obstetrics Gynecology 125(5): 1258-1267.

6. (2020) Bangladesh Demographic and Health Survey 2017-18.

7. Kangatharan C, Labram S, Bhattacharya S (2016) Interpregnancy interval following miscarriage and adverse pregnancy outcomes: systematic review and meta-analysis. Hum Reprod Update 23(2): 221-231.

8. Conde-Agudelo A, Belizan JM, Norton MH, RosasBermudez A (2005) Effect of the interpregnancy interval on perinatal outcomes in Latin America. Obstet Gynecol 106(2): 359-366.

9. Conde-Agudelo A, Rosas-Bermudez A, Kafury-Goeta AC (2006) Birth spacing and risk of adverse perinatal outcomes: a meta-analysis. JAMA 295(15): 1809-1823.

10. Kim MK, Lee SM, Bae SH, Kim HJ, Lim NG, et al. (2018) Socioeconomic status can affect pregnancy outcomes and complications, even with a universal healthcare system. Int J Equity Health 17(1): 2.

11. Zhu BP, Rolfs RT, Nangle BE, Horan JM (1999) Effect of the interval between pregnancies on perinatal outcomes. $\mathrm{N}$ Engl J Med 340(8): 589-594.

12. Luchin FW, Karen CS, Robert MS, Sunni LM, Neil JP, et al. (2015) The effect of a very short inter pregnancy interval and pregnancy outcomes following a previous pregnancy loss. Am J Obstet Gynecol 212(3): 375.e1375.e11.

13. Fuentes-Afflick E, Hessol NA (2000) Interpregnancy interval and the risk of premature infants. Obstet Gynecol 95(3): 383-390.

14. Zhu BP, Haines KM, Le T, McGrath-Miller K, Boulton ML (2001) Effect of the interval between pregnancies on perinatal outcomes among white and black women. Am J Obstet Gynecol 185(6): 1403-1410.

15. Biney AAE, Nyarko $P$ (2017) Is a woman's first pregnancy outcome related to her years of schooling? An assessment of women's adolescent pregnancy outcomes and subsequent educational attainment in Ghana. Reprod Health 14(1): 123.

16. BBS, UNICEF (2017) Ending Child Marriage in Bangladesh A Scoping Analysis of Budget Allocations. Bangladesh Bureau of Statistics and UNICEF Bangladesh.

17. Goldstein RR, Croughan MS, Robertson PA (2002) Neonatal outcomes in immediate versus delayed conceptions after spontaneous abortion: a retrospective case series. Am J Obstet Gynecol 186(6):1230-1234 discussion 1234-1236.

18. Radford EJ, Hughes M (2015) Women's experiences of early miscarriage: implications for nursing care. J Clin Nurs 24(11-12): 1457-1465.

19. (2020) Spontaneous abortion- StarPearls-NCBI Bookshelf. NBK.

20. Lippincott W, Wilkins (2012) The Johns Hopkins Manual of Gynecology and Obstetrics, pp: 438-439.

21. Silva LM, Coolman M, Steegers EA, Jaddoe VW, Moll HA, et al. (2008) Low socioeconomic status is a risk factor for preeclampsia: the generation R study. J Hypertens 26(6): 1200-1208.

22. Prior M, Bagness C, Brewin J, Coomarasamy A, Easthope L, et al. (2017) Priorities for research in miscarriage: a priority setting partnership between people affected by miscarriage and professionals following the James Lind Alliance methodology. BMJ Open 7(8): e01657.

23. Mehta M, Pattanayak RD (2013) Follow-up for Improving Psychological Well-Being for Women after a Miscarriage: rhl Commentary. The WHO Reproductive Health Library.

24. Schliep KC, Mitchell EM, Mumford SL, Radin RG, Zarek SM, et al. (2016) Trying to conceive after an early pregnancy loss; an assessment on how long couples should wait. Obstet Gynecol 127(2): 204-212.

25. Fox (1985) An Introduction to Logistic Regression Diagnostics.

26. Cox DR (1958) The Regression Analysis of Binary Sequences. Journal of the Royal Statistical Society. Series B (Methodological) 20(2): 215-232.

27. Cox DR, Hinkley DV (1974) Theoretical Statistics. Routledge Taylor \& Francis.

28. Andersen NAM, Wohlfahrt J, Christens P, Olsen J, Melbye M (2000) Maternal age and fetal loss: population based register linkage study. BMJ 320(7251): 1708-1712.

29. Fretts RC, Schmittdiel J, McLean FH, Usher RH, Goldman MB (1995) Increased maternal age and the risk of fetal death. N Engl J Med 333(15): 953-957.

30. Petitti DB (1987) The epidemiology of fetal death. Clin Obstet Gynecol 30(2): 253-258.

31. Berkowitz GS, Skovron ML, Lapinski PH, Berkowitz RL (1990) Delayed childbearing and the outcome of pregnancy. N Engl J Med 322(10): 659-664.

32. Harlap S, Shiono PH, Ramcharan S (1980) A life table of 
spontaneous abortions and the effect of age, parity and other variables. In: Porter IH (Ed.), Human embryonic and fetal death. New York: Academic Press.

33. (2014) Stillbirth: Overview, NICHD.

34. Maconochie N, Doyle P, Prior S, Simmons R (2007) Risk factors for first trimester miscarriage-results from a UKpopulation-based case-control study. BJOG 114(2): 170186.

35. Carlson E, Hoem JM, Rychtarikova J (1999) Trajectories of fetal loss in the Czech Republic. Demography 36(3): 327-337.

36. Osborn JF, Cattaruzza MS, Spinelli A (2000) Risk of spontaneous abortion in Italy, 1978-1995, and the effect of maternal age, gravidity, marital status, and education. Am J Epidemiol 151: 98-105.

37. Parazzini F, Chatenoud L, Tozzi L, Benzi G, Pino DD, et al (1997) Determinants of risk of spontaneous abortions in the first trimester of pregnancy. Epidemiology 8(6): 681-683.

38. (2018) Rural population (\%) in bangladesh. world bank staff estimates based on the united nations population division's world urbanization prospects: 2018 Revision. UN Population Division Bangladesh.

39. BBS, UNICEF (2018) Ending Child Marriage. Bangladesh Bureau of Statistics and UNICEF Bangladesh.

40. Rochebrochard EDL, Thonneau P (2002) Paternal age and maternal age are risk factors for miscarriage; results of a multicentre European study. Hum Reprod 17(6): 1649-1656.

41. Wilcox AJ, Weinberg CR, OConnor JF, Baird DD, Schlatterer JP, et al. (1988) Incidence of early loss of pregnancy. N Engl J Med 319(4): 189-194.

42. Sullivan JM, Kamilov AI (2002) DHS report Uzbekistan 2002. Induced Abortion.

43. Bentolila Y, Ratzon R, Shoham-Vardi I, Serjienko R, Mazor $M$, et al. (2013) Effect of inter pregnancy interval on outcomes of pregnancy after recurrent pregnancy loss. J Matern Fetal Neonatal Med 26(14): 1459-1464.

44. Xiangjun G, Jiahu H, Fangbiao T, Jingli Z, Hong W, et al. (2013) Pregnancy loss and anxiety and depression during subsequent pregnancies: data from the C-ABC study. Eur J Obstet Gynecol Reprod Biol 166(1): 30-36.

45. Campillo ISL, Meaney S, Sheehan J, Rice R, Donoghue KO (2018) University students' awareness of causes and risk factors of miscarriage: a cross sectional study. BMC 18: 188.

46. Cappon S, LEcluse C, Clays E, Tency I, Leye E (2015) Female genital mutilation: knowledge, attitude and practices of Flemish midwives. Midwifery 31(3): e29-35.

47. Basso 0, Olsen J, Christensen K (1998) Risk of preterm delivery, low birth weight and growth retardation following spontaneous abortion: a registry-based study in Denmark. Int J Epidemiol 27(4): 642-646. 